\title{
Efficacy of an acquainted drug in the treatment of inflammatory low back pain: sulfasalazine under investigation
}

This article was published in the following Dove Press journal:

Drug Design, Development and Therapy

23 September 2016

Number of times this article has been viewed

Jamileh Moghimi'

Ali Asghar Rezaei ${ }^{2}$

Raheb Ghorbani ${ }^{3}$

Mohammad Reza Razavi ${ }^{4}$

Daryoush Pahlevan ${ }^{3}$

'Department of Rheumatology, Clinical Research Development Unit (CRDU), ${ }^{2}$ Clinical Research Development Unit (CRDU), Kowsar Hospital, ${ }^{3}$ Social Determinants of Health Research Center, Department of Community Medicine, Faculty of Medicine; ${ }^{4}$ Nursing Care Research Center, Student Research Committee, Semnan University of Medical

Sciences, Semnan, Iran
Correspondence: Daryoush Pahlevan Social Determinants of Health Research Center, Department of Community Medicine, Faculty of Medicine, Semnan University of Medical Sciences, No 6, Abouzar St, Moalem Sq, Semnan City, Semnan Province, Iran Postal code: 241

Tel/fax +98 $2333654 I 77$

Email pahlevan.da@gmail.com
Abstract: In the current study, the overall prevalence and the main underlying etiologies of inflammatory low back pain (ILBP) were determined, and the effectiveness of treatment with sulfasalazine was investigated in patients with inflammatory versus mechanical low back pain (LBP). In a prospective study conducted from July 2013 until August 2015, 1,779 consecutive patients within the age range of $18-50$ years with a primary complaint of LBP referring to the rheumatology clinics were included. The patients were classified into two distinct groups: those suffering from ILBP $(n=118)$ and those having mechanical LBP $(n=1,661)$. Patients were followed-up for assessing the response rate to sulfasalazine with a mean follow-up time of 16 months. Results showed that among the total number of participants, $6.6 \%$ suffered from ILBP. The main underlying diagnoses of ILBP were undifferentiated spondyloarthropathy (USpA) (61.0\%) and ankylosing spondylitis (24.6\%). During the follow-up period, $3.4 \%$ of the participants had an appropriate response to only nonsteroidal anti-inflammatory drugs, $57.6 \%$ to sulfasalazine, $26.3 \%$ to addition of methotrexate to the previous regimen, and $12.7 \%$ to biological agents. Multiple logistic regression results showed that the underlying disease had a significant effect on the sulfasalazine response. The odds for response to treatment was 3.53 times higher in USpA patients compared to other patients (odds ratio $=3.53,95 \%$ confidence interval: $1.63-7.68, P=0.001)$. In $69.4 \%$ of the participants, the highest response to sulfasalazine was found, which was related to the underlying USpA. This study found that an adequate response to nonsteroidal anti-inflammatory drugs in patients with ILBP was potentially increased by adding sulfasalazine. Thus, the observed response rate was dependent on the nature of underlying spondyloarthropathy.

Keywords: low back pain, sulfasalazine, nonsteroidal anti-inflammatory drugs

\section{Introduction}

In a remarkable number of patients suffering from low back pain (LBP), a specific physiological or structural abnormality cannot be found. Although implementation of imaging strategies aids to exclude serious underlying mechanical etiologies of LBP, this complaint in majority of cases might be associated with the inflammatory processes. ${ }^{1}$ On the other hand, the observed pain in $\sim 5 \%$ of those suffering from LBP is due to the inflammation in the spinal column. ${ }^{2,3}$ The most important signs of inflammatory low back pain (ILBP) can include age at onset of back pain $<45$ years, back pain lasting $>3$ months, night pain and early morning pain, and increase in pain with exercise. ${ }^{4}$ ILBP is the main symptom of the spondyloarthopathies (SpAs). The SpAs, a diverse group of inflammatory arthritides, are of five types in adults including ankylosing spondylitis (AS), reactive arthritis ( $\operatorname{ReA})$, psoriatic arthritis (PsA), 
undifferentiated spondyloarthropathy (USpA), and SPA due to enteropathic arthritis (EnA). ${ }^{5}$

As the management and therapeutic approaches applied to mechanical LBP and ILBP are distinct, discrimination of these two types is essential. ${ }^{6}$ Nonsteroidal anti-inflammatory drugs (NSAIDs) are primarily used for the treatment of ILBP. ${ }^{7}$ However, in patients with unsatisfactory response to the mentioned drug, the regimen may be modified by addition of other drugs such as methotrexate (MTX) or sulfasalazine. ${ }^{7}$ The addition of such drugs is mostly required for patients with concomitant peripheral arthritis. ${ }^{8-10}$ Sulfasalazine can be considered as a disease-modifying antirheumatic drug, which has been effectively useful for preventing the clinical manifestations of SpA and peripheral arthritis. ${ }^{7,10}$ Recent reviews on the effectiveness of this drug have demonstrated a marked improvement in inflammatory markers such as erythrocyte sedimentation rate (ESR) as well as considerable decrease in inflammatory symptoms such as morning stiffness. ${ }^{1-14}$

In the present study, the overall prevalence and the main underlying etiologies of ILBP were determined, and the effectiveness of sulfasalazine in the treatment of patients suffering from ILBP and mechanical LBP was examined.

\section{Methods}

This prospective study involved 1,779 consecutive patients with an age range of $18-45$ years. These patients referred to the rheumatology clinics with a primary complaint of LBP (from July 2013 until August 2015). LBP was defined as any pain occurring in the region between the lower ribs and inferior gluteal folds. Patients suffering from ILBP and those having mechanical LBP were classified into two distinct groups according to the New York Criteria (Figure 1). ${ }^{6}$

Patients with any history of trauma or lumbar surgery, discopathy problems, arthrosis, or any lumbar congenital abnormalities were excluded from the study. The study was approved by the Semnan University of Medical Sciences Research Ethics Committee, and all the patients gave written informed consent. Baseline data of all the patients including demographics, disease duration, and underlying predisposing diseases were collected prior to treatment.

Moreover, all the patients were asked routine questions during a physical examination of active lumbar range of pain, motion, and stiffness. The underlying diagnoses were categorized based on specific diagnostic criteria, such as USpA, AS, and ReA.

Radiographic evaluation of lumbar and sacroiliac joints was conducted by one specialist, which led to the identification of cases with sacroilitis. Moreover, blood samples were drawn to measure serum human leukocyte antigen B27 marker, ESR, and C-reactive protein (CRP) levels. Patients were allowed to receive any NSAID at an inflammatory dose. If no response was observed within 2 weeks, another type of NSAID was prescribed. If no response was noticed again within the following 2 weeks, the patients concurrently

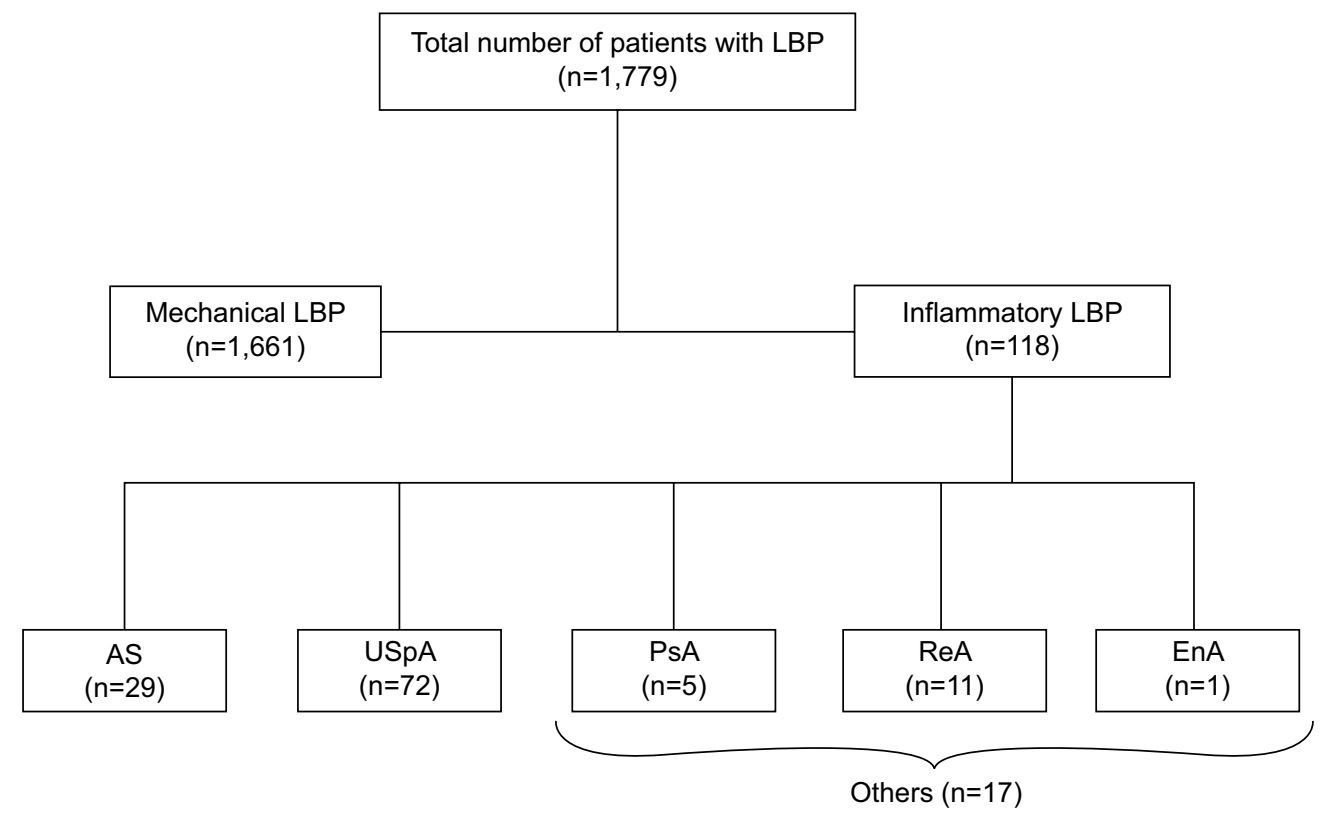

Figure I Distribution of patients who were evaluated.

Abbreviations: LBP, low back pain; AS, ankylosing spondylitis; USpA, undifferentiated spondyloarthropathy; PsA, psoriatic arthritis; ReA, reactive arthritis; EnA, enteropathic arthritis. 
received sulfasalazine $2 \mathrm{~g}$ per day. However, if no response to treatment was observed over the next 2 months, the patients were considered as resistant to sulfasalazine treatment. Response evaluation was done using Ankylosing Spondylitis Disease Activity Score (ASDAS) criteria that are based on back pain, spinal pain, peripheral pain, inflammation back pain at night, duration of morning stiffness, CRP, ESR, patient assessment of global disease activity, and fatigue. ASDAS $<1.3$ defines "inactive disease", ASDAS $\geq 1.3$ and $<2.1$ defines "moderate disease activity", ASDAS $\geq 2.1$ and $\leq 3.5$ defines "high disease activity", and ASDAS $>3.5$ defines "very high disease activity". ${ }^{15}$

Patients were subsequently followed-up for assessing response rate with a mean follow-up time of 16 months.

Data are presented as mean \pm standard error for continuous variables and as percentages for categorical variables. We analyzed the data by Shapiro-Wilk test, chi-square test, Student's $t$-test, and one-way analysis of variance. Also, multiple logistic regression analysis was performed to determine the main predictors of response to sulfasalazine. $P<0.05$ was considered statistically significant. All the statistical analyses were performed using Statistical Package for the Social Sciences (version 19.0; IBM Corporation, Armonk, NY, USA).

\section{Results}

Among 1,779 participants, 118 (6.6\%) suffered from ILBP, and 1,661 (93.3\%) patients had mechanical LBP. The patients of the ILBP group were significantly younger than the mechanical LBP group $(P<0.001)(36.2 \pm 0.9$ and $44.9 \pm 0.4$ years, respectively). The patients with ILBP had a mean disease duration of $36.3 \pm 4.2$ months. Mean age and disease duration of those with ILBP with respect to underlying disease are presented in Table 1. Moreover, among those with ILBP and mechanical LBP, 52.5\% and 19.1\% were male, respectively $(P<0.001)$.

The main underlying diagnoses of ILBP were USpA (61.0\%), AS (24.6\%), ReA (9.3\%), PsA (4.2\%), and

Table I Mean and SE of age and disease duration in patients with back pain

\begin{tabular}{|c|c|c|c|c|c|c|c|}
\hline \multirow[t]{3}{*}{ Characteristics } & \multicolumn{6}{|c|}{ Underlying disease } & \multirow[t]{3}{*}{$P$-value } \\
\hline & \multicolumn{2}{|c|}{$\begin{array}{l}\text { AS } \\
(n=29)\end{array}$} & \multicolumn{2}{|c|}{$\begin{array}{l}\text { USpA } \\
(n=72)\end{array}$} & \multicolumn{2}{|c|}{$\begin{array}{l}\text { Others }^{a} \\
(n=\mid 7)\end{array}$} & \\
\hline & Mean & SE & Mean & SE & Mean & SE & \\
\hline Age (years) & 35.9 & 1.9 & 36.2 & 1.1 & 36.8 & 1.6 & $<0.001$ \\
\hline Disease duration (months) & 67.9 & 9.7 & 28.8 & 4.7 & 14.0 & 7.1 & 0.948 \\
\hline
\end{tabular}

Notes: aReactive, psoriatic, or enteropathic arthritis. Results are in response to a one-way analysis of variance.

Abbreviations: SE, standard error; AS, ankylosing spondylitis; USpA, undifferentiated spondyloarthropathy.
EnA $(0.8 \%)$. The CRP level was significantly increased in $20.3 \%$ of patients, and ESR was also elevated in $20.3 \%$ of them. Moreover, positive human leukocyte antigen B27 was detected in $35.7 \%$ of individuals. Radiographic pictures of sacroiliac joint of all the patients were available, which revealed that $47.5 \%$ of patients had sacroiliac joint changes.

The patients with ILBP were followed-up for evaluating the response rate to different drug regimens with an average follow-up period of 16 months. During this follow-up period, four $(3.4 \%)$ patients demonstrated adequate response to only NSAIDs, 68 patients $(57.6 \%)$ showed response to both NSAIDs and sulfasalazine, 31 patients $(26.3 \%)$ revealed response to adding MTX, and 15 patients (12.7\%) were on biological agents.

Responses to sulfasalazine were significantly different with regard to the types of underlying etiologies of ILBP $(P=0.001)$. The response rates to sulfasalazine among those with ReA and USpA were $54.5 \%$ and $69.4 \%$, respectively (Figure 2). The response rate to sulfasalazine according to sex and underlying disease is presented in Table 2.

Logistic regression results showed that among all the variables, only underlying disease had a significant effect on the sulfasalazine response. The odds for response to treatment was 3.53 times higher in USpA patients compared to other patients (odds ratio $=3.53,95 \%$ confidence interval: $1.63-7.68, P=0.001)$.

\section{Discussion}

The present study clarifies a number of noteworthy issues. First, the most common underlying factors pertinent to the appearance of ILBP are USpA followed by AS.

The SpAs including AS, ReA, PsA, and USpA can be regarded as a diverse group of inflammatory arthritides, which are commonly featured by ILBP and have a specific criterion in rheumatologic field, and ILBP is a common sign in all of them. With consideration of this definition, the diagnosis of these SpAs should be mainly suspected in young patients who present with ILBP. ${ }^{16}$ Response to anti-inflammatory drugs should be considered as one of the significant criteria for differentiating mechanical LBP from ILBP. ${ }^{17}$

Second, it was revealed that with administration of NSAIDs, response rate to the treatment regimen was only $3.4 \%$, while with addition of sulfasalazine to the regimen, the response rate was significantly elevated $\sim 17$ times compared to the former regimen. Although, recent guidelines published by the Assessment of SpondyloArthritis International Society (ASAS) recommend NSAIDs as first-line agents for treatment of axial and peripheral manifestations 


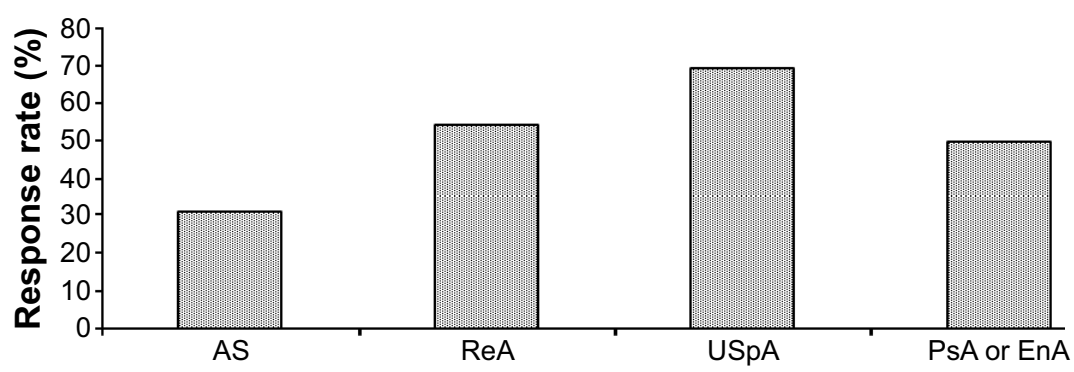

Figure 2 Response rate (\%) to sulfasalazine with respect to underlying diseases in low back pain patients.

Abbreviations: AS, ankylosing spondylitis; ReA, reactive arthritis; USpA, undifferentiated spondyloarthropathy; PsA, psoriatic arthritis; EnA, enteropathic arthritis.

of SpA, and sulfasalazine and MTX are disease-modifying antirheumatic drugs considered for the treatment of AS and other forms of SpAs. Also, the efficacy of sulfasalazine in axial SpA is similar to MTX; it is not recommended in the most recent ASAS guidelines for axial disease. ${ }^{18}$

Sulfasalazine is useful in AS patients who do not respond to or who have contraindications to NSAIDs, as well as in those with coexisting EnA. In particular, it is often given to treat peripheral joint involvement, for which it has demonstrated efficacy, but there is no evidence that it improves spinal mobility, enthesitis, or physical function. ${ }^{19}$

According to the conducted studies, in patients with SpAs, the combination therapy with sulfasalazine is more effective than either NSAID alone or its combination with MTX. With respect to the baseline characteristics, only the underlying predisposing factor was the main determinant of response to sulfasalazine in patients suffering from ILBP. On the other hand, the highest and the lowest response rates to this drug were observed in patients with EnA and AS, respectively. Some previously conducted studies showed that the type and nature of underlying diagnosis as well as the type of involved joints can predict how well the patients will respond to sulfasalazine. It has been demonstrated that sulfasalazine might have higher effects on ILBP in patients without peripheral joint disease. ${ }^{11}$

Table 2 Response rate to sulfasalazine in patients with back pain according to sex and underlying disease

\begin{tabular}{|c|c|c|c|c|c|c|}
\hline \multirow[t]{3}{*}{ Sex } & \multirow{3}{*}{$\begin{array}{l}\text { Underlying } \\
\text { disease }\end{array}$} & \multirow[t]{3}{*}{$\mathbf{N}$} & \multicolumn{4}{|c|}{ Response to sulfasalazine } \\
\hline & & & \multicolumn{2}{|c|}{ Positive } & \multicolumn{2}{|c|}{ Negative } \\
\hline & & & $\mathbf{n}$ & $\%$ & $\mathbf{n}$ & $\%$ \\
\hline \multirow[t]{3}{*}{ Female } & AS & 29 & 9 & 31.0 & 20 & 69.0 \\
\hline & USpA & 23 & 11 & 47.8 & 12 & 52.2 \\
\hline & Others $^{\mathrm{a}}$ & 10 & 6 & 60.0 & 4 & 40.0 \\
\hline \multirow[t]{3}{*}{ Male } & AS & - & - & - & - & - \\
\hline & USpA & 49 & 39 & 79.6 & 10 & 20.4 \\
\hline & Others ${ }^{a}$ & 7 & 3 & 42.9 & 4 & 57.1 \\
\hline
\end{tabular}

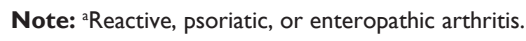

Abbreviations: AS, ankylosing spondylitis; USpA, undifferentiated spondyloarthropathy.
The results of Benitez-Del-Castillo et al study on patients with an average of 10 years of AS without peripheral joint disease demonstrated that more patients reported successful treatment with sulfasalazine as it is more effective than placebo in the treatment of severe LBP. ${ }^{20}$ In another randomized controlled trial conducted by Clegg et al, it was shown that sulfasalazine was effective for peripheral arthritis in patients with AS, PsA, and ReA; however, it was not markedly different from placebo in the subset of patients with predominantly axial disease. The observed finding can be possibly attributable to the longer and more advanced disease in the patients with AS. ${ }^{13}$ Also, in a study by Braun et al, sulfasalazine was no better than placebo for the treatment of the signs and symptoms of USpA; however, sulfasalazine was more effective than placebo in the subgroup of patients with ILBP and no peripheral arthritis. ${ }^{11}$ Most of the studies is about ILBP in AS patients, but Brent and Kalagate in their study investigated sulfasalazine's effect on all kinds of SpAs. They found that sulfasalazine is useful in USpA (similar to our study) and EnA. ${ }^{21}$

Nissilä et al studied 85 AS patients with relatively short disease duration and found that the sulfasalazine group reported less morning stiffness after 26 weeks of treatment and inflammatory markers were seen to fall significantly. ${ }^{22}$ An earlier randomized controlled trial on patients with an average of 10 years of AS without peripheral joint disease found that considerably more patients reported treatment with sulfasalazine to be more effective than placebo. ${ }^{20}$

It seems that the association between the type of SpAs and the response rate to sulfasalazine might interact with the duration and severity of the underlying diagnosis, which requires to be evaluated in further studies. To put in a nutshell, the present study reveals that the underlying SpAs play a crucial role in the appearance of ILBP. It is also found that response to anti-inflammatory drugs in rheumatoid arthritis patients is potentially increased by adding sulfasalazine to the former drugs. This response rate is also dependent on the nature of the underlying SpA. 


\section{Limitations}

A limitation of this study was low sample size in some background groups, so evaluation of treatment response in all groups was impossible.

\section{Conclusion}

Currently, biologic drugs such as anti-TNF $\alpha$ are recommended for the treatment of patients with SpA accompanying ILBP, but these drugs are not easily available and are of high costs. The results of our study showed that use of sulfasalazine with or without NSAIDs may reduce treatment complications, especially in the cases of USpA, and is also cost-effective.

\section{Acknowledgments}

The authors would like to express their gratitude to the staff of Kowsar Hospital and Clinical Research Development Unit (CRDU) under supervision of Semnan University of Medical Sciences for their cooperation.

\section{Author contributions}

All authors contributed toward data analysis, drafting and critically revising the paper and agree to be accountable for all aspects of the work.

\section{Disclosure}

The authors report no conflicts of interest in this work.

\section{References}

1. Riksman JS, Williamson OD, Walker BF. Delineating inflammatory and mechanical sub-types of low back pain: a pilot survey of fifty low back pain patients in a chiropractic setting. Chiropr Man Ther. 2011;19(1):5.

2. Calin A, Kaye B, Sternberg M, Antell B, Chan M. The prevalence and nature of back pain in an industrial complex: a questionnaire and radiographic and HLA analysis. Spine. 1980;5(2):201-205.

3. Sidiropoulos P, Hatemi G, Song I-H, et al. Evidence-based recommendations for the management of ankylosing spondylitis: systematic literature search of the $3 \mathrm{E}$ Initiative in Rheumatology involving a broad panel of experts and practising rheumatologists. Rheumatology. 2008;47(3):355-361.
4. Lee YC. Effect and treatment of chronic pain in inflammatory arthritis. Curr Rheumatol Rep. 2013;15(1):300.

5. Sieper J, van der Heijde D, Landewe R, et al. New criteria for inflammatory back pain in patients with chronic back pain: a real patient exercise by experts from the Assessment of SpondyloArthritis international Society (ASAS). Ann Rheum Dis. 2009;68(6):784-788.

6. Walker BF, Williamson OD. Mechanical or inflammatory low back pain. What are the potential signs and symptoms? Man Ther. 2009;14(3): 314-320.

7. Chou R. Pharmacological management of low back pain. Drugs. 2010;70(4):387-402.

8. Last AR, Hulbert K. Chronic low back pain: evaluation and management. Am Fam Physician. 2009;79(12):1067-1074.

9. Peretz A. [Inflammatory low back pain]. Rev Med Brux. 2007;28(4) 290-293. French.

10. Schlossbauer T, Panteleon A, Becker-Gaab C. [Inflammatory spine disease as a cause of back pain]. Radiologe. 2006;46(6):468-479. German.

11. Braun J, Zochling J, Baraliakos X, et al. Efficacy of sulfasalazine in patients with inflammatory back pain due to undifferentiated spondyloarthritis and early ankylosing spondylitis: a multicentre randomised controlled trial. Ann Rheum Dis. 2006;65(9):1147-1153.

12. Dougados M, vam der Linden S, Leirisalo-Repo M, et al. Sulfasalazine in the treatment of spondylarthropathy. A randomized, multicenter, double-blind, placebo-controlled study. Arthritis Rheum. 1995;38(5): 618-627.

13. Clegg DO, Reda DJ, Abdellatif M. Comparison of sulfasalazine and placebo for the treatment of axial and peripheral articular manifestations of the seronegative spondylarthropathies: a Department of Veterans Affairs cooperative study. Arthritis Rheum. 1999;42(11):2325-2329.

14. Chen J, Liu C. Sulfasalazine for ankylosing spondylitis. Cochrane Database Syst Rev. 2005;(2):CD004800.

15. Machado $P$, van der Heijde $D$. How to measure disease activity in axial spondyloarthritis? Curr Opin Rheumatol. 2011;23(4):339-345.

16. van der Linden S, van der Heijde D. Ankylosing spondylitis: clinical features. Rheum Dis Clin North Am. 1998;24(4):663-676.

17. Dougados M, Dijkmans B, Khan M, Maksymowych W, Van der Linden S, Brandt J. Conventional treatments for ankylosing spondylitis. Ann Rheum Dis. 2002;61(Suppl 3):iii40-iii50.

18. Keith MP. Overview of drug therapy for spondyloarthritis. Rheumatol Curr Res. 2013;3:119.

19. Chen J, Liu C. Is sulfasalazine effective in ankylosing spondylitis? A systematic review of randomized controlled trials. J Rheumatol. 2006; 33(4):722-731.

20. Benitez-Del-Castillo JM, Garcia-Sanchez J, Iradier T, Bañares A. Sulfasalazine in the prevention of anterior uveitis associated with ankylosing spondylitis. Eye (Lond). 2000;14(Pt 3A):340-343.

21. Brent LH, Kalagate R. Ankylosing spondylitis and undifferentiated spondyloarthropathy. Available from: emedicine.medscape.com/ article/332945-overview. Accessed November 3, 2009.

22. Nissilä M, Lehtinen K, Leirisalo-Repo M, Luukkainen R, Mutru O, Yli-Kerttula U. Sulfasalazine in the treatment of ankylosing spondylitis. Arthritis Rheum. 1988;31(9):1111-1116.

\section{Publish your work in this journal}

Drug Design, Development and Therapy is an international, peerreviewed open-access journal that spans the spectrum of drug design and development through to clinical applications. Clinical outcomes, patient safety, and programs for the development and effective, safe, and sustained use of medicines are the features of the journal, which

\section{Dovepress}

has also been accepted for indexing on PubMed Central. The manuscript management system is completely online and includes a very quick and fair peer-review system, which is all easy to use. Visit http://www.dovepress.com/testimonials.php to read real quotes from published authors. 